\title{
Formulação de bebida láctea fermentada sabor pêssego utilizando substratos alternativos e cultura probiótica
}

\author{
Formulation of a peach-flavored dairy drink using alternative substrates and probiotic culture

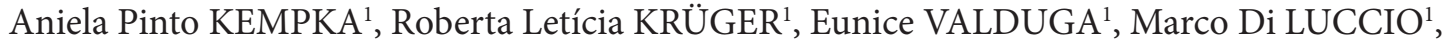 \\ Helen TREICHEL ${ }^{1}$, Rogério CANSIAN ${ }^{2}$, Débora de OLIVEIRA ${ }^{1 *}$
}

\begin{abstract}
Resumo
Atualmente, são lançados no mercado diversos novos produtos, sendo que, especificamente na área de laticínios, ênfase tem sido dada ao desenvolvimento de produtos funcionais. Concernente à amplitude deste tema, o presente trabalho possui como objetivo geral o desenvolvimento de uma bebida láctea fermentada com características probióticas. Além disso, propõe-se a utilização de soro de leite e extrato hidrossolúvel de soja como substratos, agregando valor às matérias-primas de baixo custo, com características funcionais apontadas na literatura. Para tal, utilizou-se a técnica do planejamento de experimentos para obter a formulação de bebida láctea, utilizando como substratos leite de vaca, soro de leite e extrato hidrossolúvel de soja. A formulação contendo $30 \%$ de extrato hidrossolúvel de soja, 36,6\% de leite de vaca e 33,3\% de soro de leite foi definida como ideal em termos de análise sensorial e avaliação do crescimento celular. Análises organolépticas, microbiológicas e físico-químicas definiram a vida útil do produto. Durante o período de armazenamento, a bebida láctea sabor pêssego apresentou células viáveis da cultura mista adicionada dentro dos padrões estabelecidos $\left(1 \times 10^{6} \mathrm{UFC}_{\mathrm{mL}}^{-1}\right)$ até o $22^{\circ}$ dia. A qualidade físicoquímica apresentou pequenas alterações, sendo que a acidez ficou bastante evidenciada a partir do $22^{\circ}$ dia de armazenamento. A qualidade sensorial definiu o término do armazenamento no $14^{\circ}$ dia, pelo fato da bebida já apresentar acidez elevada, sendo rejeitada nas análises sensoriais. A bebida láctea sabor pêssego desenvolvida teve uma vida útil de aproximadamente 14 dias, sem adição de conservante.
\end{abstract}

Palavras-chave: bebida láctea; formulação; probiótico; Bifidobacterium.

\begin{abstract}
Nowadays, new food products are launched in the market, and the main focus of the dairy industry is on functional products. Thus, the first objective of this work was to develop a fermented dairy drink with probiotic characteristics. Furthermore, milk serum and soy hidrosoluble extract were used as substrates increasing the value of low cost raw materials that have functional features, as reported in the literature. Based on these aspects, an experimental design was used to investigate the formulation of a peach- flavored dairy drink using milk serum, cow milk and soy hidrosoluble extracts. The formulation with $30 \%$ of soy hidrosoluble extract, $36.6 \%$ of cow milk and $33.3 \%$ of milk serum was found as ideal in terms of sensorial analysis and cell growth evaluation. Organoleptical, physicochemical, and microbiological analyses determined the shelf-life of the product. During the storage period, the peach- flavored dairy drink presented viable cells according to the Legislation $\left(1 \times 106\right.$ UFC.mL $\left.\mathrm{m}^{-1}\right)$ for 22 days. The physicochemical quality changed slightly since the acidity presented high values after the 22 nd day. The sensorial quality defined the shelf life as 14 days without the addition conservants due to the high acidity value of the fermented dairy drink determined.

Keywords: probiotic; formulation; dairy drink; Bifidobacterium.
\end{abstract}

\section{Introdução}

$\mathrm{Na}$ área de laticínios, uma nova tendência que vem se apresentando é a produção de iogurtes e leites fermentados funcionais. Isto porque, além destes produtos possuírem grande aceitação pelo público em geral e apresentarem excelente valor nutritivo, são veículos em potencial para o consumo de probióticos (ANTUNES et al., 2007). Segundo Heller (2001), os consumidores estão familiarizados com o fato de que alimentos fermentados podem apresentar microrganismos vivos.

Apenas iogurtes e leites fermentados contendo culturas probióticas devem ser considerados funcionais (ANTUNES; CAZETTO; CARDELLO, 2004). No entanto, os consumidores em geral não sabem distinguir quais são os produtos lácteos funcionais.
Uma questão ainda não concluída pela literatura é a quantidade e freqüência de consumo de probióticos necessários para assegurar os benefícios funcionais a eles atribuídos (GILLILAND; REILLY; KIM, 2002). Preconiza-se a ingestão semanal mínima de 300 a $500 \mathrm{~g}$ de produtos lácteos fermentados contendo entre $10^{6}$ a $10^{7}$ UFC. $\mathrm{mL}^{-1}$. No Brasil, dos diversos leites fermentados disponíveis no mercado, apenas alguns contêm no rótulo a identificação do microrganismo presente. Em geral, o fabricante limita-se a informar que o produto contém "fermentos lácteos". No entanto, a linhagem do microrganismo presente no produto, bem como o número de células viáveis desta cultura é que determinam se este é ou não funcional.

Recebido para publicação em 23/5/2007

Aceito para publicação em 19/10/2007 (002550)

Departamento de Engenharia de Alimentos, Universidade Regional Integrada - URI, Campus de Erechim, Av. Sete de Setembro, 1621, CEP 99700-000, Erechim - RS, Brasil,

E-mail: odebora@uricer.edu.br

2 Centro de Tecnologia, Instituto de Química, Universidade Federal do Rio de Janeiro - UFRJ, CEP 21945-970, Rio de Janeiro - RJ, Brasil

${ }^{*}$ A quem a correspondência deve ser enviada 
Neste contexto, as investigações científicas mais recentes têm demonstrado clara e inequivocamente a relevância para a saúde de dois microrganismos probióticos: Bifidobacterium, uma bifidobactéria (da família de bactérias benéficas presentes na flora intestinal do cólon) e Lactobacillus acidophilus (presente na flora intestinal do intestino delgado). Estas bactérias têm ações que se potencializam mutuamente, isto é, têm entre si uma relação de simbiose.

Por outro lado, os produtos à base de soja exemplificam as características que se buscam nos alimentos funcionais. Além de possuírem uma proteína em quantidade e qualidade, melhoram os aspectos de funcionalidade dos alimentos e o seu consumo regular contribui para diminuir os níveis de colesterol e triglicerídeos, prevenindo também certos tipos de câncer. Além das vitaminas e minerais, a soja é também fonte de fibras com propriedades funcionais.

Aliado à utilização do extrato hidrossolúvel de soja no desenvolvimento de novos produtos com características funcionais, as proteínas do soro de leite também contribuem para reduzir o colesterol sangüíneo oferecendo certa proteção contra as doenças cardiovasculares. $\mathrm{O}$ uso de produtos de soro, além dos benefícios nutricionais, oferece uma boa relação custo/ benefício.

Neste contexto, o objetivo deste trabalho foi desenvolver uma bebida láctea fermentada sabor pêssego, com características funcionais, utilizando como substratos soro de leite, extrato hidrossolúvel de soja e leite de vaca.

\section{Material e métodos}

\subsection{Matérias-primas}

As matérias-primas utilizadas na composição do substrato para fermentação foram: leite de vaca, extrato hidrossolúvel de soja e soro de leite. Utilizou-se leite UHT desnatado, adquirido em estabelecimentos comerciais.

O extrato hidrossolúvel de soja foi produzido no Laboratório de Análise Sensorial do Centro Tecnológico da URI - Campus de Erechim, seguindo metodologia indicada pela EMATER regional.

O soro de leite, subproduto da produção de queijo tipo lanche, foi gentilmente cedido pela Empresa COOCEL (Cooperativa de Prestação de Serviços, Industrialização, Comercialização e Consultoria do Alto Uruguai Ltda, Erechim - RS).

\subsection{Culturas láticas}

Utilizou-se uma cultura mista de Streptococcus thermophilus, Lactobacillus delbrueckii subsp. bulgaricus, Lactobacillus acidophilus e Bifidobacterium, sendo representada pelos nomes comerciais MY Bio 6 e MY Bio 2, procedente da Rhodia Brasil Ltda.

A cultura apresentava-se liofilizada e procedeu-se sua reativação em leite em pó desengordurado após este ter sido hidratado e esterilizado em autoclave a $121^{\circ} \mathrm{C}$ por 15 minutos e conservado em estufa por 24 horas à temperatura de $37^{\circ} \mathrm{C}$; procedimento este efetuado de acordo com recomendações do fornecedor. Após este período, o inóculo foi repicado em caldo MRS (Man, Rogosa e Sharp - MERCK) estéril, sendo utilizado $1 \mathrm{~mL}$ de inóculo para $10 \mathrm{~mL}$ de meio, sendo este mantido em estufa a $37^{\circ} \mathrm{C}$ por mais 24 horas. Após esta etapa, os pré-inóculos foram conservados em geladeira, à temperatura de refrigeração, até o momento de sua utilização.

\subsection{Métodos}

Os métodos físico-químicos e os demais métodos utilizados nas etapas de produção da bebida fermentada, acompanhamento da evolução da fermentação e da estabilidade da bebida fermentada são descritos a seguir.

\section{Determinação do $\mathrm{pH}$}

Os valores de $\mathrm{pH}$ foram determinados em potenciômetro digital (Gehaka), devidamente calibrado com soluções tampão de $\mathrm{pH}$ 7,0 e 4,0 (NORMAS ANALÍTICAS DO INSTITUTO ADOLFO LUTZ, 1985).

\section{Determinação da acidez total}

A determinação da acidez total foi realizada medindose o teor de ácido lático presente em $100 \mathrm{~g}$ de amostra, pela titulação com $\mathrm{NaOH} 0,1 \mathrm{~N}$ de alíquota de $5 \mathrm{~mL}$ de amostra, na presença de fenolftaleína como indicador (BOLETIM DE BIOTECNOLOGIA, 1999).

\section{Determinação da densidade ótica}

A Densidade Ótica (DO) foi determinada como o aumento da turbidez da amostra, medida em espectrofotômetro (Agilient Tecnologies) em comprimento de onda de $650 \mathrm{~nm}$.

\section{Obtenção do extrato hidrossolúvel de soja}

O fluxograma de obtenção do extrato hidrossolúvel de soja é apresentado na Figura 1. A metodologia empregada na obtenção deste foi desenvolvida a partir de dados obtidos na EMATER regional, cujo processamento foi realizado manualmente. Primeiramente foi realizada a limpeza e a seleção dos grãos de soja para posterior obtenção do extrato hidrossolúvel. Aos grãos limpos foi adicionada água e levou-se à fervura por 5 minutos. Em seguida, foi realizada lavagem em água corrente e posterior adição de água e realização de nova fervura. Em uma próxima etapa, os grãos foram triturados e foi adicionado, a esta mistura, bicarbonato de sódio. A adição de bicarbonato de sódio $\left(\mathrm{NaHCO}_{3}\right)$ foi realizada para promover a inativação da enzima lipoxigenase, responsável pelo sabor indesejável de feijão cru, característico da soja (MACEDO, 1997). A mistura foi então filtrada, cozida por 10 minutos, adicionada de sal e açúcar e, posteriormente, homogeneizada.

\section{Desproteinização do soro de leite}

O soro de leite utilizado foi o soro proveniente da fabricação do queijo tipo lanche. Após a coleta, este material foi aquecido 
a $80{ }^{\circ} \mathrm{C}$ por 15 minutos e, posteriormente, filtrado, a fim de se promover a separação da proteína (TORTELLI, 2002).

\section{Tratamento térmico dos substratos}

O tratamento térmico foi realizado para a mistura de extrato hidrossolúvel de soja, soro de leite e leite de vaca nas devidas proporções. $\mathrm{O}$ pH da mistura foi corrigido para 7,5 com $\mathrm{NaOH}$ 0,4 N. Em seguida, as amostras de substrato foram pasteurizadas em erlenmeyer de $500 \mathrm{~mL}$ em banho-maria a $80^{\circ} \mathrm{C}$ por 20 minutos (MACEDO, 1997).

\section{Otimização dos fatores de operação em meio sintético}

O objetivo desta etapa foi otimizar o crescimento da cultura mista de S. thermophilus, L. delbrueckii subsp. bulgaricus, L. acidophilus e Bifidobacterium, visando obter as melhores condições de operação para a referida cultura. Para isto, foi utilizada

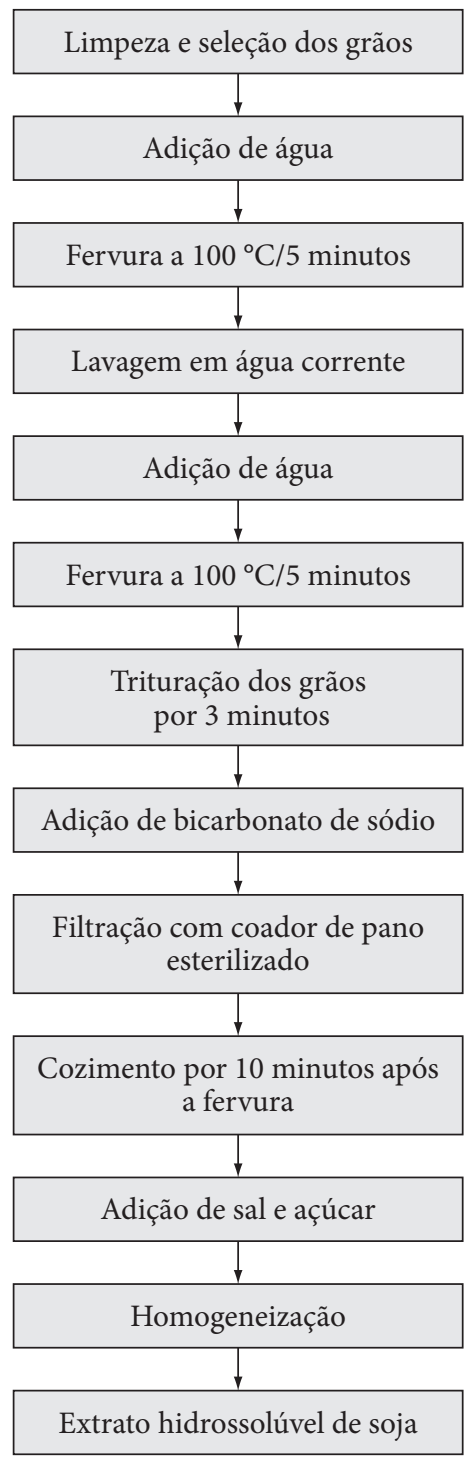

Figura 1. Fluxograma do processo de obtenção do extrato hidrossolúvel de soja. a técnica de planejamento de experimentos, avaliando o efeito da temperatura, pH e agitação sobre o crescimento celular. A análise estatística dos dados experimentais permitiu otimizar as condições operacionais em função do crescimento celular. Posteriormente, esses dados foram utilizados para determinar as condições operacionais para produção da bebida láctea.

O intervalo de estudo destes fatores foi definido em função de resultados apresentados na literatura (TORTELLI, 2002). Visando avaliar as variáveis de processo no crescimento celular, um planejamento experimental completo com 2 níveis e 3 variáveis foi empregado. A Tabela 1 apresenta o intervalo de estudo das variáveis.

Para cada experimento descrito foi utilizado $1 \mathrm{~mL}$ de inóculo para cada $50 \mathrm{~mL}$ de caldo MRS. As amostras foram mantidas em agitador orbital em temperatura e agitação controladas e foram retiradas de 2 em 2 horas para avaliação do crescimento celular e pH. O crescimento celular foi avaliado através da densidade ótica (DO), a qual foi determinada através de leituras de absorbância das amostras em espectrofotômetro $(\lambda=650 \mathrm{~nm})$ e $\mathrm{pH}$ em potenciômetro digital. Em uma primeira etapa foram realizados os experimentos apresentados na Tabela 2 .

\section{Planejamento das formulações}

Após determinadas as condições de operação mais favoráveis para o crescimento da cultura láctea, empregou-se outro planejamento experimental (Tabela 3), visando obter a concentração ideal de cada um dos substratos na formulação da bebida láctea.

Visando a otimização da mistura, dois novos planejamentos (Tabelas 4 e 5) foram necessários para se obter uma formulação base.

\section{Obtenção da bebida láctea fermentada e aromatização}

A formulação otimizada, após a mistura, foi pasteurizada a $80{ }^{\circ} \mathrm{C}$ por 20 minutos. As amostras foram então resfriadas à

Tabela 1. Intervalo de estudo das variáveis.

\begin{tabular}{lrrr}
\hline & $(-1)$ & $(0)$ & $(+1)$ \\
\hline Temperatura $\left({ }^{\circ} \mathrm{C}\right)$ & 30,0 & 36,0 & 42,0 \\
Agitação $(\mathrm{rpm})$ & 0,0 & 100,0 & 200,0 \\
$\mathrm{pH}$ & 5,5 & 6,5 & 7,5 \\
\hline
\end{tabular}

Tabela 2. Matriz do planejamento experimental para otimização dos fatores (valores reais e codificados).

\begin{tabular}{clcc}
\hline Ensaio & $\mathrm{T}\left({ }^{\circ} \mathrm{C}\right)$ & $\mathrm{pH}$ & Agitação $(\mathrm{rpm})$ \\
\hline 1 & $30(-1)$ & $5,5(-1)$ & $0(-1)$ \\
2 & $42(1)$ & $5,5(-1)$ & $0(-1)$ \\
3 & $30(-1)$ & $5,5(-1)$ & $200(1)$ \\
4 & $42(1)$ & $5,5(-1)$ & $200(1)$ \\
5 & $30(-1)$ & $7,5(1)$ & $0(-1)$ \\
6 & $42(1)$ & $7,5(1)$ & $0(-1)$ \\
7 & $30(-1)$ & $7,5(1)$ & $200(1)$ \\
8 & $42(1)$ & $7,5(1)$ & $200(1)$ \\
9 & $36(0)$ & $6,5(0)$ & $100(0)$ \\
\hline
\end{tabular}


temperatura de $40^{\circ} \mathrm{C}$ e, a estas, adicionado o estabilizante Carragena (DCA - Indústria e Comércio Ltda) na proporção de $0,1 \mathrm{~g}$ para cada $100 \mathrm{~mL}$ de produto, padrão obtido na Legislação para produtos fermentados (TORTELLI, 2002). Foram adicionados $2 \%$ de inóculo para a mistura selecionada. A mistura obtida foi acondicionada em agitador orbital nas condições de operação estabelecidas.

A bebida foi aromatizada com aroma artificial de pêssego (RCC 88439/1, RHODIA BRASIL Ltda), colorida com corante artificial laranja e amarelo (ARCOLOR) e, em seguida, foi adicionada a polpa de pêssego (MAIS FRUTA) e adoçante (sacarose). Para aromatização da bebida láctea sabor pêssego, realizouse um planejamento de experimentos, variando a concentração de polpa (11,5 a 20 g.200 mL $\left.\mathrm{mL}^{-1}\right)$ e de açúcar $\left(5\right.$ a 15 g.200 mL $\left.\mathrm{mL}^{-1}\right)$. As concentrações de aroma e de corante utilizadas foram as indicadas nos rótulos dos produtos.

A matriz do planejamento experimental (valores reais e codificados) para cada experimento de aromatização da bebida láctea sabor pêssego é apresentada na Tabela 6 .

A avaliação sensorial foi realizada pela utilização de escala estruturada de 9 pontos, com 10 a 15 provadores selecionados e amostras com codificação balanceada com dois dígitos, cujas características avaliadas no perfil de características foram: aparência: homogeneidade e aspecto; sabor: global, soja e

Tabela 3. Planejamento experimental para obtenção da formulação base da bebida láctea - etapa 1 .

\begin{tabular}{cccc}
\hline Experimento & $\begin{array}{c}\text { Extrato hidrossolúvel } \\
\text { de soja }(\%)\end{array}$ & $\begin{array}{c}\text { Soro de leite } \\
(\%)\end{array}$ & $\begin{array}{c}\text { Leite de vaca } \\
(\%)\end{array}$ \\
\hline 1 & 50 & 40 & 10 \\
2 & 40 & 50 & 10 \\
3 & 10 & 50 & 40 \\
4 & 10 & 40 & 50 \\
5 & 40 & 10 & 50 \\
6 & 50 & 10 & 40 \\
7 & 33 & 33 & 33 \\
\hline
\end{tabular}

Tabela 4. Planejamento experimental para obtenção da formulação base para a bebida láctea fermentada (otimização) - etapa 2 .

\begin{tabular}{cccc}
\hline Ensaio & $\begin{array}{c}\text { Extrato hidrossolúvel } \\
\text { de soja }(\%)\end{array}$ & $\begin{array}{c}\text { Soro de leite } \\
(\%)\end{array}$ & $\begin{array}{c}\text { Leite de vaca } \\
(\%)\end{array}$ \\
\hline 1 & 25 & 25 & 50 \\
2 & 33 & 33 & 33 \\
3 & 22 & 45 & 33 \\
4 & 30 & 45 & 25 \\
\hline
\end{tabular}

Tabela 5. Planejamento experimental para obtenção da formulação base para a bebida láctea fermentada (otimização) - etapa 3.

\begin{tabular}{cccc}
\hline Ensaio & $\begin{array}{c}\text { Extrato hidrossolúvel } \\
\text { de soja }(\%)\end{array}$ & $\begin{array}{c}\text { Soro de leite } \\
(\%)\end{array}$ & $\begin{array}{c}\text { Leite de vaca } \\
(\%)\end{array}$ \\
\hline 1 & 25,0 & 30,0 & 45,0 \\
2 & 33,3 & 30,0 & 36,6 \\
3 & 30,0 & 25,0 & 45,0 \\
4 & 30,0 & 33,3 & 36,7 \\
\hline
\end{tabular}

ácido; aroma: global, soja e ácido; e textura: consistência e aceitabilidade (avaliação global) pelo teste de Escala Hedônica de 9 pontos ( 1 - desgostei muitíssimo e 9 - gostei muitíssimo). Os dados obtidos foram analisados estatisticamente pelo teste ANOVA, com nível de confiança de 95\%. Através da análise sensorial e análise de variância definiu-se a aromatização para a bebida láctea.

\section{Avaliação da estabilidade da bebida láctea}

A bebida fermentada sabor pêssego foi armazenada sob refrigeração $\left(4^{\circ} \mathrm{C}\right)$, em copos plásticos de $250 \mathrm{~mL}$, para avaliação de sua estabilidade físico-química, microbiológica e sensorial, realizada a partir do primeiro dia, nos intervalos de 7, 14, 19 e 22 dias de estocagem, respectivamente.

\section{Estabilidade físico-química}

A estabilidade físico-química da bebida foi avaliada em amostras coletadas ao acaso e homogeneizadas previamente às determinações de pH e acidez total (\% ácido láctico).

\section{Estabilidade microbiológica}

A avaliação microbiológica da bebida láctea sabor pêssego foi realizada paralelamente à avaliação físico-química e organoléptica, em amostras coletadas ao acaso. $\mathrm{O}$ número de células da microflora essencial presente na bebida, S. thermophilus, L. delbrueckii, subsp. bulgaricus, L. acidophilus e Bifidobacterium foi determinado pela contagem total de células viáveis. Diferentes diluições da amostra em água peptonada $0,1 \%$ foram efetuadas, conforme o tempo de fermentação, através de testes prévios realizados, para que fosse possível a contagem das colônias. Assim, $1 \mathrm{~mL}$ de amostra, nas diluições estabelecidas, foi semeado em placa de Petri com meio MRS agar em camadas. As placas invertidas foram incubadas em jarras de anaerobiose, contendo gerador de atmosfera de $\mathrm{CO}_{2}$, dentro de estufa a $42^{\circ} \mathrm{C}$ por 48 horas (MACEDO, 1997).

As demais determinações microbiológicas foram efetuadas de acordo com metodologia descrita por Silva et al. (1999), em que se avaliou a presença de coliformes fecais (NMP), Salmonella e contagem de bolores e leveduras.

Tabela 6. Matriz do planejamento experimental (valores reais e codificados) para cada experimento de aromatização da bebida sabor pêssego.

\begin{tabular}{clc}
\hline Experimento & Polpa $(\mathrm{g})$ & Açúcar $(\mathrm{g})$ \\
\hline 1 & $11,5(-1)$ & $7,9(-1)$ \\
2 & $11,5(-1)$ & $22,0(1)$ \\
3 & $18,5(1)$ & $7,9(-1)$ \\
4 & $18,5(1)$ & $22,0(1)$ \\
5 & $15,0(0)$ & $5,0(-1,41)$ \\
6 & $15,0(0)$ & $25,0(1,41)$ \\
7 & $10,0(-1,41)$ & $15,0(0)$ \\
8 & $20,0(1,41)$ & $15,0(0)$ \\
9 & $15,0(0)$ & $15,0(0)$ \\
10 & $15,0(0)$ & $15,0(0)$ \\
11 & $15,0(0)$ & $15,0(0)$ \\
\hline
\end{tabular}




\section{Estabilidade sensorial}

A ocorrência de alterações no sabor, aroma, aparência e textura da bebida durante o período de armazenamento foi determinada pela avaliação sensorial. As amostras foram escolhidas ao acaso, homogeneizadas, distribuídas em copos plásticos, com codificação balanceada e apresentadas à equipe de provadores selecionados. Os atributos aparência, textura, aroma e sabor em escala estruturada foram avaliados.

A estabilidade das características sensoriais da bebida láctea fermentada sabor pêssego, durante a estocagem, foi investigada nos tempos de armazenamento de 0, 7, 14, 19 e 22 dias.

\section{Resultados e discussão}

\subsection{Otimização dos fatores de operação em meio sintético}

Os dados cinéticos referentes aos experimentos estão apresentados na Figura 2. Conforme pode ser visualizado, a temperatura e a agitação apresentaram grande influência sobre

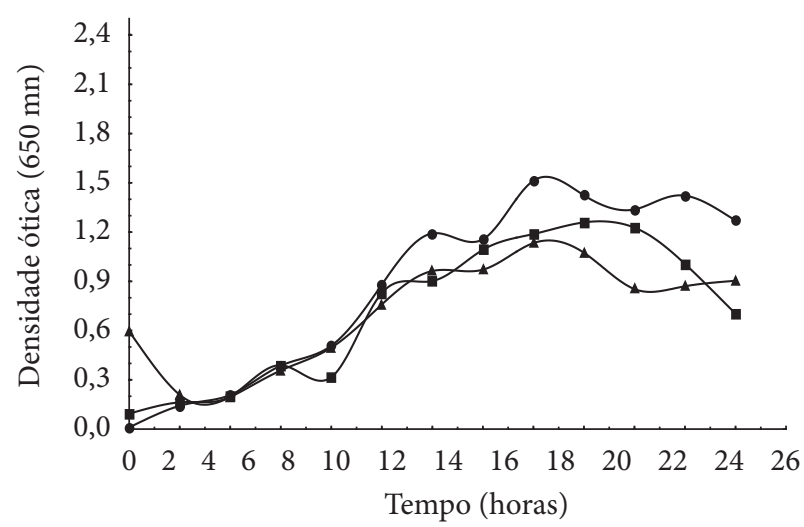

$$
\begin{aligned}
& \leftarrow \mathrm{pH}=5.5, \mathrm{~T}=30^{\circ} \mathrm{C}, \text { agit }=200 \mathrm{rpm} \\
& -\mathrm{pH}=7.5, \mathrm{~T}=30^{\circ} \mathrm{C}, \text { agit }=200 \mathrm{rpm} \\
& \leftarrow \mathrm{pH}=6.5, \mathrm{~T}=36^{\circ} \mathrm{C}, \text { agit }=100 \mathrm{rpm}
\end{aligned}
$$

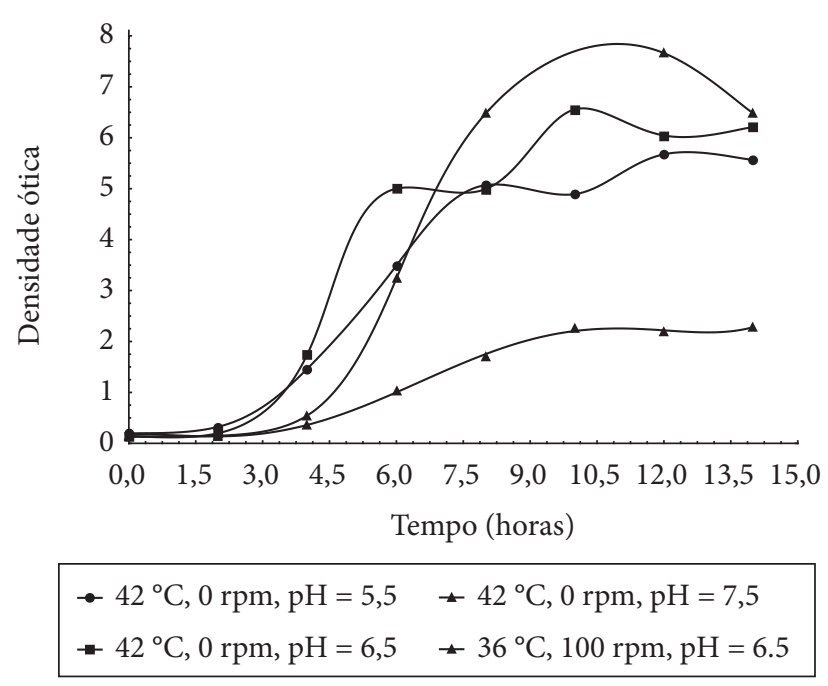

Figura 2. Crescimento celular (unidades de absorbância x tempo). o crescimento celular. De forma geral, em temperaturas mais elevadas obteve-se crescimento mais acentuado. Em relação à agitação, o maior crescimento se deu quando não se empregou agitação, mostrando que esta cultura é anaeróbica.

Para verificar a influência das variáveis de processo no crescimento celular, foi realizada a análise estatística dos dados experimentais. Os resultados estão apresentados na Tabela 7. Neste ponto, cabe frisar que a análise foi realizada para um tempo de 18 horas, fase exponencial de crescimento para todas as condições experimentais.

O desvio padrão médio dos parâmetros foi em torno de 0,02 para as faixas estudadas. A análise estatística dos dados experimentais confirmou que a temperatura e a agitação foram os fatores que mais afetaram o crescimento celular, sendo que a temperatura apresentou efeito positivo e a agitação um efeito negativo no crescimento celular, este último foi um resultado já esperado, já que as culturas lácteas são anaeróbicas facultativas. Já a interação entre as variáveis temperatura e agitação resultou em um efeito negativo. Com os resultados obtidos, pode-se concluir que quando há utilização desta cultura mista em meio MRS, a condição que maximiza o crescimento celular é a temperatura de $42^{\circ} \mathrm{C}, \mathrm{pH}$ inicial de 7,5 , sem agitação.

\subsection{Planejamento das formulações}

A formulação base foi definida com base no crescimento celular como aquela referente ao Experimento 4 (Tabela 5): $30 \%$ de extrato hidrossolúvel de soja, $33,3 \%$ de soro de leite e $36,7 \%$ de leite de vaca.

\subsection{Aromatização da bebida láctea}

A Tabela 8 apresenta a resposta da aceitabilidade média atribuída para cada experimento de aromatização da bebida láctea.

Tabela 7. Modelo estatístico experimental.

\begin{tabular}{ccccccc}
\hline $\mathrm{R}=0,99859$ & \multicolumn{6}{c}{ Modelo: } \\
& $\mathrm{DO} 18=\mathrm{a}_{0}+\mathrm{a}_{1}{ }^{*} \mathrm{~T}+\mathrm{a}_{2}{ }^{*} \mathrm{pH}+\mathrm{a}_{3}{ }^{*}$ agit $+\mathrm{a}_{4}{ }^{*} \mathrm{~T}^{*}$ agit $+\mathrm{a}_{5}{ }^{*} \mathrm{pH}^{*} \mathrm{pH}$ \\
\hline Parâmetro & $\mathrm{a}_{0}$ & $\mathrm{a}_{1}$ & $\mathrm{a}_{2}$ & $\mathrm{a}_{3}$ & $\mathrm{a}_{4}$ & $\mathrm{a}_{5}$ \\
& 0,769 & 1,218 & 0,164 & $-1,570$ & $-1,145$ & 1,061 \\
\hline
\end{tabular}

$\mathrm{T}=$ temperatura; agit = agitação; $\mathrm{e} \mathrm{pH}=\mathrm{pH}$.

Tabela 8. Resposta da aceitabilidade média.

\begin{tabular}{cc}
\hline Experimento & Aceitabilidade global \\
\hline 1 & 5,71 \\
2 & 5,93 \\
4 & 6,79 \\
5 & 2,43 \\
6 & 6,50 \\
7 & 5,86 \\
8 & 3,57 \\
9 & 5,93 \\
10 & 6,86 \\
11 & 7,26 \\
\hline
\end{tabular}


Através dos resultados de aceitabilidade, a aromatização da bebida láctea sabor pêssego foi definida com $15 \mathrm{~g}$ de açúcar, $15 \mathrm{~g}$ de polpa de pêssego, $0,1 \mathrm{~mL}$ de aroma e $0,1 \mathrm{~mL}$ de corante para $200 \mathrm{~mL}$ de bebida.

As Figuras 3 e 4 apresentam, respectivamente, a superfície de resposta e a curva de contorno para a aceitabilidade global.

\subsection{Estabilidade da bebida láctea}

\section{Estabilidade físico-química}

De acordo com a Figura 5, pode-se observar que durante o período de estocagem da bebida, o $\mathrm{pH}$ apresentou diminuições consideráveis, sendo que o $\mathrm{pH}$ inicial para a bebida láctea sabor pêssego foi de 4,93, chegando a $\mathrm{pH} 4,32$ no $19^{\circ}$ dia de armazenamento.

A partir de 22 dias de estocagem, verificou-se acentuada acidificação do produto, comprovada pela avaliação das

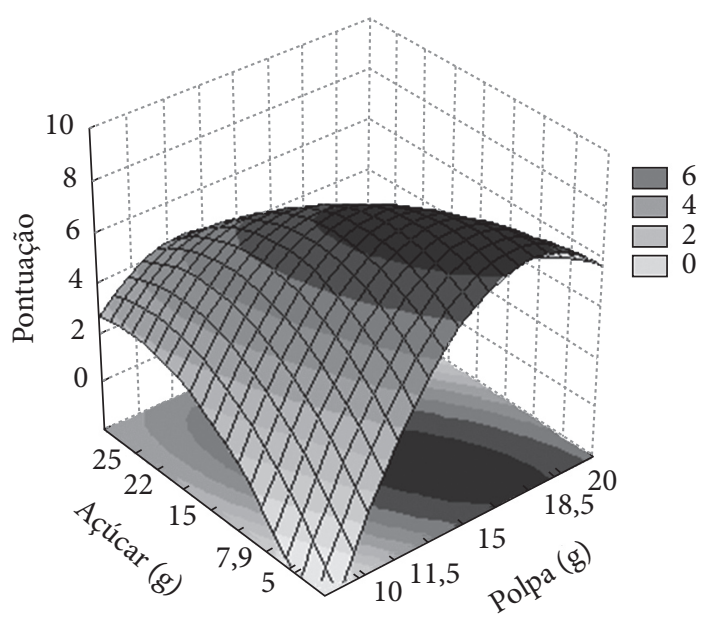

Figura 3. Superfície de resposta para a aceitabilidade global da bebida láctea de pêssego.

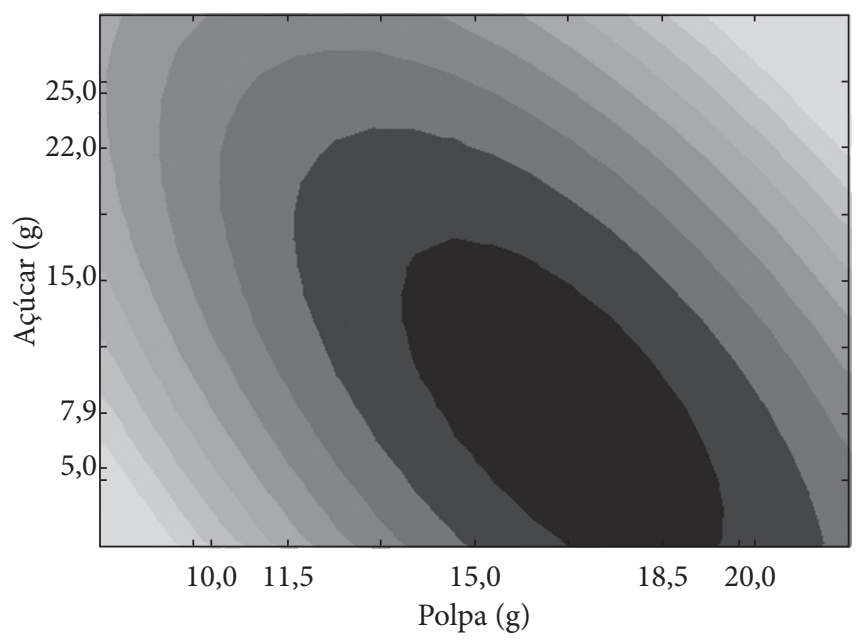

Figura 4. Curva de contorno para a aceitabilidade global da bebida láctea de pêssego. características organolépticas, causando a desestabilidade da estrutura protéica e sua coagulação, visto que as proteínas do leite apresentam ponto isoelétrico em $\mathrm{pH}$ próximo a 4,6 e as da soja, pH 5,2 (ANVISA, 2001).

A elevada acidez e o baixo $\mathrm{pH}$, aos 22 dias de armazenamento, possivelmente estejam relacionados à ação do Lactobacilus acidophilus, microrganismo conhecido pela grande capacidade de produção de ácido no meio da fermentação. Devido à sua característica de alta acidez, os produtos acidófilos são apreciados por um grupo restrito de consumidores (MACEDO, 1997).

O uso de bifidobactérias em culturas mistas, principalmente com lactobacilos, proporciona a formação de ácido L (+) láctico e as propriedades benéficas associadas a estas bactérias intestinais (MACEDO, 1997). A utilização de bactérias bífidas em culturas mistas possibilita a produção de compostos voláteis que mascaram o sabor e o aroma característico da soja em misturas fermentadas (ANGELES; MARTH, 1971).

Tortelli (2002), em um estudo com cultura mista de S. thermophilus e L. delbrueckii subsp. bulgaricus, utilizando a formulação base para a bebida láctea de 55\% de extrato hidrossolúvel de soja, $35 \%$ de leite de vaca e $10 \%$ de soro de leite, mostrou que durante o armazenamento a qualidade físicoquímica apresentou alterações significativas. Pelo fato da bebida inicialmente já apresentar um baixo valor de $\mathrm{pH}$, a acidez ficou bem evidenciada a partir do $7^{\circ}$ dia. Constatou-se, no $10^{\circ}$ dia de armazenamento, que a aparência e homogeneidade permaneceram praticamente inalteradas, havendo também pouca alteração no aroma global e ácido, porém o sabor apresentou alterações significativas no que diz respeito ao sabor de soja.

Zacarchenco (2004), em estudo com leites fermentados por Streptococcus thermophilus, Bifidobacterium longum e Lactobacillus acidophilus, constatou que os menores valores de $\mathrm{pH}(4,19)$ e os maiores de acidez titulável $(135,5)$ foram encontrados no leite fermentado por Streptococcus thermophilus, enquanto o leite fermentado por Bifidobacterium longum apresentou a menor acidez titulável $(70,3)$ e o maior $\mathrm{pH}(5,06)$ aos 21 dias de estocagem, valores próximos aos encontrados neste estudo.

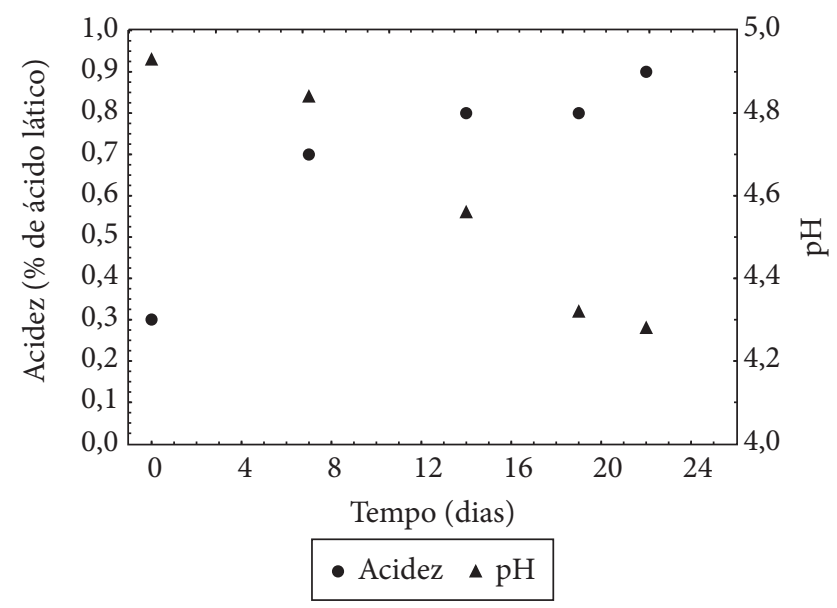

Figura 5. Relação entre pH e acidez durante o armazenamento da bebida láctea sabor pêssego. 
Comportamento semelhante também foi observado por Bonassi et al. (2001), que analisaram as características físicoquímicas de bebidas lácteas fermentadas e preparadas com soro de queijo minas frescal. Foi observado que ocorre inicialmente aumento e posterior diminuição da glicose, formação de oligossacarídeos, queda do $\mathrm{pH}$ e aumento na acidez titulável durante a incubação e armazenamento (28 dias).

\section{Estabilidade microbiológica}

A contagem de probióticos é de fundamental importância para que seja possível a verificação quanto à legislação em vigor, além da sua influência no sabor e aroma. As diferentes formulações das bebidas podem selecionar de maneira positiva ou negativa o crescimento dos microrganismos.

A Tabela 9 apresenta o comportamento da cultura mista da bebida láctea no decorrer do armazenamento.

A contagem final de células viáveis na bebida fermentada, aos 22 dias de estocagem, mostrou-se dentro dos limites recomendados para este produto, tornando-o atrativo como adjunto na dieta humana.

Contagens um pouco superiores foram obtidas por Silva et al. (2001) em estudo com leites fermentados por uma cultura mista composta de S. thermophilus, L. delbrueckii subsp. bulgaricus e L. acidophilus. A contagem total de células viáveis totalizou $10^{8}$ UFC. $\mathrm{mL}^{-1}$.

Segundo Penna (2005), Streptococcus thermophilus e Lactobacillus delbrueckii subsp. bulgaricus exibem uma relação denominada protocooperação, durante a produção da bebida, já que não existe dependência entre os dois para a sua sobrevivência. Essas bactérias produzem mais ácido na forma de cultura mista do que ao serem utilizadas como culturas isoladas. Em estudo variando a concentração de soro, açúcar e frutooligossacarídeos sobre a população de bactérias lácticas probióticas em bebidas fermentadas, $\mathrm{o}$ autor obteve contagens na ordem de $10^{12} \mathrm{UFC} . \mathrm{mL}^{-1}$. Cabe ressaltar, que em todas as formulações apresentadas no trabalho de Penna (2005) foi adicionado estabilizante.

Barreto et al. (2003) afirmaram que ainda não se observa a alegação de propriedade funcional na maioria dos produtos colocados no mercado e, para que isso possa ocorrer no futuro, é importante que a legislação brasileira considere a inclusão de um valor limite mínimo para a contagem das cepas probióticas declaradas. Nesse caso, é necessário e extremamente relevante que sejam avaliados e implantados no país métodos diferenciais de quantificação das espécies de maior interesse.

Os resultados das análises microbiológicas realizadas ao longo do período de armazenamento estão apresentados na Tabela 10.

Tabela 9. Desenvolvimento da cultura mista na bebida láctea no decorrer do armazenamento.

\begin{tabular}{lccccc}
\hline \multicolumn{6}{c}{ Tempo de armazenamento (dias) } \\
\hline Células viáveis & 0 & 7 & 14 & 19 & 22 \\
$\left(\right.$ UFC.mL $\left.^{-1}\right)$ & $2,5 \times 10^{7}$ & $1,2 \times 10^{7}$ & $4,5 \times 10^{6}$ & $4,2 \times 10^{6}$ & $1 \times 10^{6}$ \\
\hline
\end{tabular}

Assim, de acordo com a Resolução no ${ }^{\circ}$, de 2 de janeiro de 2001 da Agência Nacional de Vigilância Sanitária (ANVISA), a bebida láctea apresentou padrões microbiológicos situados dentro dos limites estabelecidos para leites fermentados, mostrando excelente qualidade microbiológica, mantida durante o período de estocagem estabelecido para cada formulação.

\section{Estabilidade sensorial}

Os resultados da análise descritiva quantitativa, perfil de características da formulação no decorrer do armazenamento, são apresentados na Tabela 11.

A Figura 6 apresenta a estabilidade sensorial do produto. No $14^{\circ}$ dia constatou-se mudança nos atributos aspecto, aroma de soja e sabor global, sendo a bebida láctea sabor pêssego estável por aproximadamente 14 dias.

Macedo (1997) manteve, com a formulação base de uma bebida láctea de $35 \%$ de leite de vaca, $35 \%$ de soro de leite de búfula e $30 \%$ de extrato hidrossolúvel de soja e a combinação das culturas $L$. casei shirota e B. adolescentis, uma estabilidade físico-química, microbiológica e sensorial até o $28^{\circ}$ dia de armazenamento.

Tortelli (2002), com a formulação base de 55\% de extrato hidrossolúvel de soja, $35 \%$ de leite de vaca e $10 \%$ de soro de leite e a cultura mista $S$. thermophilus e $L$. delbrueckii susbp. Bulgaricus, obteve para a bebida láctea desenvolvida, estabilidade físico-química, microbiológica e sensorial até o $7^{\circ}$ dia de armazenamento.

Tabela 10. Avaliação da estabilidade microbiológica durante o armazenamento da bebida láctea.

\begin{tabular}{lccccc}
\hline & \multicolumn{5}{c}{ Tempo de armazenamento (dias) } \\
\cline { 2 - 6 } & 0 & 7 & 14 & 19 & 22 \\
\hline Coliformes totais $^{* *}$ & $\mathrm{~A}^{*}$ & $\mathrm{~A}$ & $\mathrm{~A}$ & $\mathrm{~A}$ & $\mathrm{~A}$ \\
Coliformes fecais $^{* *}$ & $\mathrm{~A}$ & $\mathrm{~A}$ & $\mathrm{~A}$ & $\mathrm{~A}$ & $\mathrm{~A}$ \\
Salmonella $($ em $25 \mathrm{~g})$ & $\mathrm{A}$ & $\mathrm{A}$ & $\mathrm{A}$ & $\mathrm{A}$ & $\mathrm{A}$ \\
Bolores e leveduras $^{* * *}$ & $\mathrm{~A}$ & $\mathrm{~A}$ & $\mathrm{~A}$ & $3,6 \times 10^{3}$ & $4,9 \times 10^{3}$ \\
\hline
\end{tabular}

${ }^{*} \mathrm{~A}=$ Ausente; ${ }^{* *}$ Coliformes totais e fecais: NMP.mL ${ }^{-1} ; e^{* * *}$ Bolores e leveduras: UFC. $\mathrm{mL}^{-1}$.

Tabela 11. Análise descritiva quantitativa - perfil de características.

\begin{tabular}{lccc}
\hline Características & \multicolumn{3}{c}{ Tempo de armazenamento (dias) } \\
\cline { 2 - 4 } & 0 & 7 & 14 \\
\hline Aparência & & & \\
Homogeneidade & $5,00^{\mathrm{a}}$ & $3,75^{\mathrm{a}}$ & $3,63^{\mathrm{a}}$ \\
$\quad$ Aspecto & $5,16^{\mathrm{a}}$ & $4,63^{\mathrm{ab}}$ & $3,72^{\mathrm{b}}$ \\
Textura & & \\
$\quad$ Consistência & $5,33^{\mathrm{a}}$ & $3,72^{\mathrm{b}}$ & $3,20^{\mathrm{c}}$ \\
Aroma & & & \\
$\quad$ Global & $6,33^{\mathrm{a}}$ & $6,58^{\mathrm{a}}$ & $6,27^{\mathrm{a}}$ \\
$\quad$ Soja & $5,41^{\mathrm{a}}$ & $4,36^{\mathrm{ab}}$ & $3,60^{\mathrm{b}}$ \\
$\quad$ Ácido & $4,08^{\mathrm{a}}$ & $5,27^{\mathrm{a}}$ & $4,10^{\mathrm{a}}$ \\
Sabor & & & \\
$\quad$ Global & $6,08^{\mathrm{ab}}$ & $6,81^{\mathrm{a}}$ & $4,81^{\mathrm{b}}$ \\
$\quad$ Soja & $4,75^{\mathrm{a}}$ & $4,20^{\mathrm{a}}$ & $4,00^{\mathrm{a}}$ \\
Ácido & $4,50^{\mathrm{a}}$ & $5,58^{\mathrm{a}}$ & $4,81^{\mathrm{a}}$ \\
\hline
\end{tabular}




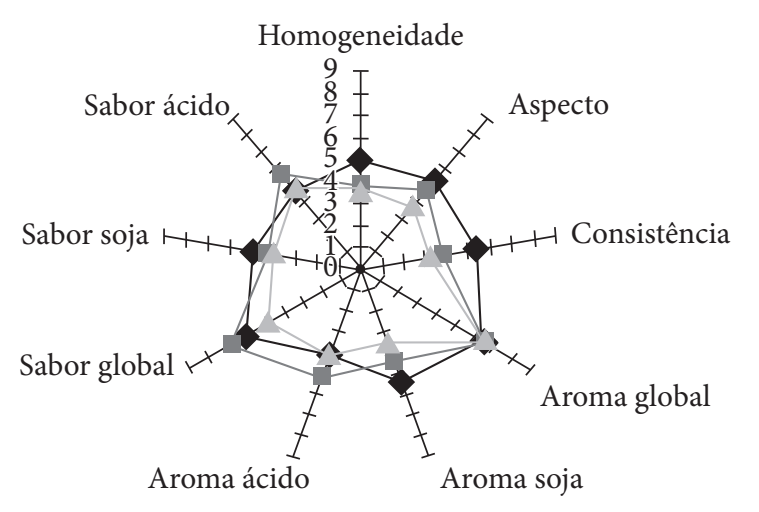

0 dia $\longrightarrow 7$ dias

Figura 6. Estabilidade organoléptica da bebida láctea fermentada sabor pêssego.

Zacarchenco (2004), utilizando cultura de Streptococcus thermophilus, Bifidobacterium longum e Lactobacillus acidophilus em leites fermentados, obteve aceitação das formulações contendo Bifidobacterium longum e Lactobacillus acidophilus pelos provadores até o $21^{\circ}$ dia de estocagem, com o produto armazenado a $4{ }^{\circ} \mathrm{C}$.

Assim, a bebida láctea desenvolvida neste estudo apresentou um tempo de prateleira significativo, representando um resultado satisfatório, considerando o fato de não se ter adicionado nenhum conservante no produto.

\section{Conclusões}

O crescimento da cultura mista de $S$. thermophilus, L. delbrueckii subsp. bulgaricus, L. acidophilus e Bifidobacterium em caldo MRS atingiu seu máximo crescimento em 4 horas de incubação nas condições de temperatura de $42^{\circ} \mathrm{C}$, sem agitação e com pH inicial de 7,5.

A formulação contendo $30 \%$ de extrato hidrossolúvel de soja, $36,6 \%$ de leite de vaca e $33,3 \%$ de soro de leite foi adotada como sendo a formulação base ideal determinada por análise sensorial e avaliação do crescimento celular durante a fermentação.

Durante o período de armazenamento, a bebida láctea sabor pêssego apresentou células viáveis da cultura mista adicionada dentro dos padrões estabelecidos $\left(1 \times 10^{6} \mathrm{UFC} \cdot \mathrm{mL}^{-1}\right)$ até o $22^{\circ}$ dia.

A qualidade físico-química apresentou pequenas alterações. Pelo fato da bebida inicialmente já apresentar um baixo valor de $\mathrm{pH}(4,93)$, a acidez ficou bastante evidenciada a partir do $22^{\circ}$ dia de armazenamento. A qualidade sensorial definiu o término do armazenamento no $14^{\circ}$ dia, já que a bebida apresentou uma acidez bastante elevada ( $0,9 \%$ de ácido lático), em torno de três vezes maior que a inicial, sendo rejeitada nas análises sensoriais. Assim, a bebida láctea sabor pêssego desenvolvida teve uma vida útil de aproximadamente 14 dias sem adição de conservante.

\section{Referências bibliográficas}

ANGELES, A. G.; MARTH, E. H. Growth and activity of lactic-acid bacteria in soymilk. Growth and acid production. Journal of Milk Food Technology, v. 34, n. 1, p. 30-36, 1971.

ANTUNES, A. E. C.; CAZETTO, T. F.; CARDEllO, H. M. A. B. Iogurtes desnatados probióticos adicionados de concentrado protéico do soro de leite: perfil de textura, sinerese e análise sensorial. Alimentos e Nutrição, v. 15, n. 2, p. 105-114, 2004.

ANTUNES, A. E. C. et al. Desenvolvimento de buttermilk probiótico. Ciência e Tecnologia de Alimentos, v. 27, n. 1, p. 83-90, 2007.

ANVISA - Agência Nacional de Vigilância Sanitária. Disponível em: <http:// www.anvisa.com.br>.

BARRETO, G. P. M. et al. Quantificação de Lactobacillus acidophilus, Bifidobactérias e Bactérias Totais em Produtos Probióticos Comercializados no Brasil. Brazilian Journal of Food Technology, v. 6, n. 1, p. 119-126, 2003.

Sociedade Portuguesa de Biotecnologia. Boletim de Biotecnologia, n. $64,1999$.

BONASSI, I. A.; ALMEIDA, K. E.; ROCA, R. O. Características físicas e químicas de bebidas lácteas fermentadas e preparadas com soro de queijo minas frescal. Ciência e Tecnologia de Alimentos, v. 21, n. 2, p. 187-192, 2001.

GILLILAND, S. E.; REILLY, S. S.; KIM, H. S. Viability during storage of selected probiotic lactobacilli and bifidobacteria in yogurt-like product. Food Microbiology and Safety, v. 67, n. 8, p. 3091-3095, 2002.

HELLER, K. J. Probiotic bactéria in fermented foods: product characteristics and starter organisms. The American Journal of Clinical Nutrition, v. 73, n. 2, p. 374-379, 2001.

MACEDO, R. E. F. Desenvolvimento de bebida láctea fermentada a base de extrato hidrossolúvel de soja e soro de leite de búfala por cultura mista de Lactobacillus casei Shirota e Bifidobacterium adolescentis. Curitiba, 1997. Dissertação - (Mestrado), Universidade Federal do Paraná.

NAIDU, A. S.; BIDLACK, W. R.; CLEMENS, R. A. Probiotic spectra of lactic acid bacteria (LAB). Critical Review in Food Science, v. 38, n. 1, p. 13-126, 1999.

INSTITUTO ADOLFO LUTZ. Normas Analíticas do Instituto Adolfo Lutz. Métodos Químicos e Físicos para análise de Alimentos. 3 ed. São Paulo, 1985.

PENNA, A. L. B.; THAMER, K. G. Efeito do teor de soro, açúcar e de frutooligossacarídeos sobre a população de bactérias lácticas probióticas em bebidas fermentadas. Revista Brasileira de Ciências Farmacêuticas, v. 41, n. 3, p. 393-400, 2005.

SAXELIN, M.; KORPELA, R.; MAYARA-MAKINEN, A. Introduction: classifying functional dairy products. In: MATILLA-SANDHOLM, T.; SAARELA, M. (Eds.). Functional Dairy Products. New York, Boca Raton: American Dietetic Association, 2003.

SILVA, M. R. et al. Elaboração e avaliação de uma bebida láctea fermentada à base de soro de leite fortificada com ferro. Revista do Instituto de Laticínios Cândido Tostes, v. 56, n. 1, p. 7-14, 2001.

TORTELLI, S. Desenvolvimento de Bebidas Lácteas Fermentadas Utilizando como Substrato Extrato Hidrossolúvel de Soja e Soro de Leite. Erechim - RS, 2002 Monografia (Graduação), Universidade Regional Integrada do Alto Uruguai e das Missões.

ZACARCHENCO, P. B.; MASSAGUER-ROIG, S. Avaliação sensorial, microbiológica e de pós-acidificação durante a vida-de-prateleira de leites fermentados contendo Streptococcus thermophilus, Bifidobacterium longum e Lactobacillus acidophilus. Ciência e Tecnologia de Alimentos, v. 38, n. 1, p. 674-679, 2004. 